\title{
The temperature-gradient metamorphism of snow: vapour diffusion model and application to tomographic images
}

\author{
Frédéric FLIN, Jean-Bruno BRZOSKA ${ }^{\dagger}$ \\ Météo-France/Centre National de Recherches Meteorologiques/Centre d'Etudes de la Neige, 1441 rue de la Piscine, \\ 38400 Saint-Martin-d'Hères Cedex, France \\ E-mail: frederic.flin@meteo.fr
}

\begin{abstract}
A simple physical model describing the temperature-gradient metamorphism of snow is presented. This model, based on Kelvin's equation and Fick's law, takes into account the local variation of the saturating vapour pressure with temperature. It can determine locally whether the ice is condensing or subliming, depending on both the pressure and temperature fields in the snow structure. This model can also explain the formation of facets that occurs during the metamorphism. Using X-ray microtomographic images of snow samples obtained under low to moderate temperature-gradient conditions, this model has been tested and compared to the reaction-limited model proposed in a previous work.
\end{abstract}

\section{INTRODUCTION}

Of the different types of metamorphism that may occur in snow, the temperature-gradient (TG) metamorphism is probably the most interesting. Typically occurring on cold clear nights, when the TG between the top and the bottom of the snow layer is high, this metamorphism is characterized by the formation of facets at the bottom of the grains while upper parts remain rounded (Yosida and others, 1955; Colbeck, 1983).

Despite significant interest from the snow and ice community (see the introduction of Sommerfeld, 1983, for a detailed review), TG metamorphism remains poorly understood. In particular, two fundamental questions have not been fully answered. First, what is the driving force for the matter exchange in the ice matrix and what are the associated mechanisms? Second, what determines concretely whether wellrounded or faceted shapes can appear?

These two questions were addressed and partly resolved by Colbeck (1983) more than 20 years ago, but the results were based on two-dimensional (2-D) observations and very simple approximations on the snow geometry. In our approach, we would like to take advantage of X-ray microtomographic techniques and revisit these questions by using high-resolution three-dimensional (3-D) images.

In a preceding work (Flin and others, 2007), we proposed a 3 -D model based on the Langmuir-Knudsen equation implying that the matter exchange is limited by surface reaction mechanisms. When applied to 3-D images of snow structures, this model gave realistic results. However, the main mechanism is generally considered to be vapour diffusion in the pore space.

In order to clarify the importance of the mechanisms involved in the TG metamorphism, we now propose a new model that assumes vapour diffusion in pore space as the main limiting mechanism.

In the following, we first present a simple model that estimates the matter fluxes in a snow sample submitted to temperature gradients and address the faceting issue using standard concepts of crystal growth. We then recall the TG experiment and the $\mathrm{X}$-ray microtomographic measurements

${ }^{\dagger}$ Deceased. that allowed us to produce 3-D images of the metamorphosed snow structures. Finally, we apply our model to some of these snow images and compare the diffusion-limited results to the surface reaction-limited results obtained in our previous paper (Flin and others, 2007).

\section{PHYSICAL MODEL}

\subsection{Origin of the matter transfer inside snow}

The basic idea behind this model is the same as presented in Flin and others (2007): snow crystals grow (respectively decrease) by the condensation (sublimation) of vapour on their bottom (top) portions because they are colder (warmer) than the surrounding air. In the present model, the main limiting mechanism is considered to be the vapour diffusion through the pore space, which is usually assumed in the literature (e.g. de Quervain, 1973; Colbeck, 1997; Legagneux and Dominé, 2005).

We also make the following assumptions:

1. The latent heat is quickly removed through the highly conductive ice (Colbeck, 1983).

2. The convection effects in the pore space are negligible (Brun and Touvier, 1987; Kaempfer and others, 2005).

3. The temperature dependence of the diffusion coefficient can be neglected.

4. Thermodiffusion effects can be neglected, according to de Quervain (1963)

In order to quantify the matter transfer at the ice-pore interface, we can express the incoming matter flux $j\left(\mathrm{~kg} \mathrm{~m}^{-2} \mathrm{~s}^{-1}\right)$ on a point of the ice surface using Fick's law:

$$
j=-\rho_{\mathrm{vap}} D \vec{\nabla} C \cdot \vec{n},
$$

where $\rho_{\text {vap }}, D$ and $c$ are the density $\left(\mathrm{kg} \mathrm{m}^{-3}\right)$, diffusion coefficient $\left(\mathrm{m}^{2} \mathrm{~s}^{-1}\right)$ and the concentration in number $\left(\mathrm{mol} \mathrm{mol}^{-1}\right)$ of water vapour close to the ice surface, respectively. $\vec{n}$ represents the local outward normal vector on the ice interface and $\vec{\nabla}$ is the gradient operator. 


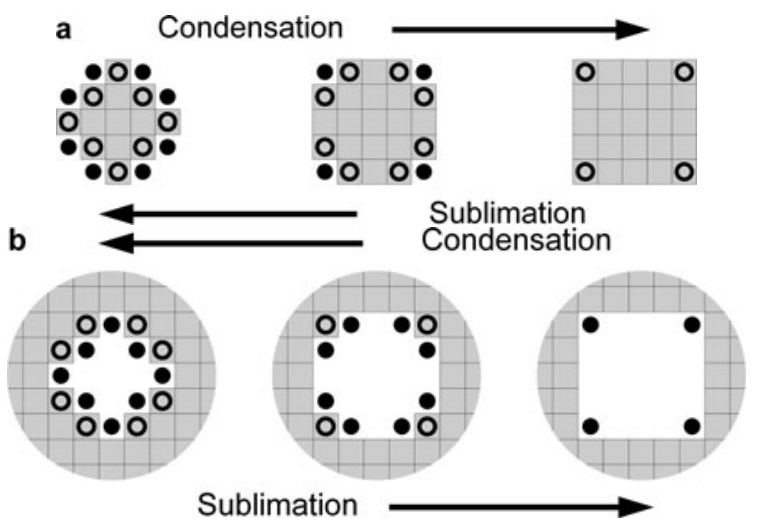

Fig. 1. Faceting model based on Kossel crystal explanation. Circles and dots correspond to preferential sublimation and condensation sites, respectively. (a) For convex shapes, condensation leads to faceting while sublimation generates a rounding of the grains. (b) For concave shapes, the reverse behaviour is observed.

Since both air and vapour can be considered as ideal gases, Fick's law can be rewritten as follows:

$$
j=-\frac{\rho_{\mathrm{vap}} D}{\rho_{\mathrm{air}} \mathrm{R}} \vec{\nabla}\left(\frac{P}{T}\right) \cdot \vec{n},
$$

where $\mathrm{R}$ is the universal gas constant $\left(\mathrm{J} \mathrm{mol}^{-1} \mathrm{~K}^{-1}\right)$ and $\rho_{\text {air }}$ is the density of air $\left(\mathrm{kg} \mathrm{m}^{-3}\right) . P$ and $T$ are the vapour pressure and vapour temperature, respectively.

The matter flux $j$ incoming to the ice surface depends on the vapour-pressure and temperature fields, which are not uniform in the considered snow volume. By computing these fields, one can then use Equation (2) to obtain the local matter fluxes incoming to each point of the ice surface.

\subsection{Faceting and rounding effects}

To address the problem of grain faceting, we used a classical atomistic approach based on the Terrace Ledge Kink (TLK) or Kossel crystal model (Markov, 1995; Mutaftschiev, 2001). The main results, initially presented by Knight (1966), are summarized as follows (Fig. 1):

1. During the growth of a convex Kossel crystal (Table 1, a), some sites (such as step or kink sites) are energetically more likely to adsorb atoms than flat surfaces. This results in a layer-by-layer process and a production of facets.

2. Conversely, the sublimation of such a convex crystal (Table 1, b) will begin by removing the step and kink sites. This will produce new kink and step sites, and finally lead to an atomically rough surface, i.e. a macroscopically rounded interface.

3. For concave crystals, the preferential adsorption (Table 1, c) or removal (Table 1, d) of kink and step sites will result in opposite behaviours to those obtained for convex crystals.

The validity of Table 1 is confirmed by the following common observations.

1. 'Negative' faceted crystals have been obtained by sublimation of concave ice shapes by inserting a hypodermic needle inside ice volumes and connecting it to a vacuum (Knight and Knight, 1965; Furukawa and Kohata, 1993).
Table 1. Surface aspect depending on the sign of both the incoming flux $j$ and the interface curvature $C$

\begin{tabular}{lll}
\hline & Condensation $(j>0)$ & Sublimation $(j<0)$ \\
\hline Convexity $(C>0)$ & a. Faceting & b. Rounding \\
Concavity $(C<0)$ & c. Rounding & d. Faceting \\
\hline
\end{tabular}

2. The isothermal metamorphism, which results only in condensation on concavities (Table 1b) and sublimation on convexities (Table 1c) due to Kelvin's law, is characterized by significant surface rounding.

As far as TG metamorphism is concerned, the situation is more complex as the regimes presented in Table 1 can operate at the same time. However, the sign of the flux $j$ can determine the faceting or the rounding of shapes depending on the sign of the local curvature $C\left(\mathrm{~m}^{-1}\right)$ of the interface. For a snow structure imaged in three dimensions, one can compute the local incoming flux $j$ with the help of Equation (2). It is then possible to check the aspect of the surface depending on the sign of the computed flux.

In order to check the validity of our model, we submitted snow to a temperature gradient and imaged the obtained samples.

\section{TEMPERATURE-GRADIENT METAMORPHISM EXPERIMENT}

\subsection{Sample preparation}

A 3 week experiment on TG metamorphism was run at Col de Porte, French Alps, in order to provide precise microtomographic 3-D data for the validation of TG metamorphism models.

Snow was sieved into a specially designed cool box, which is able to generate several TGs in a single experiment. This insulated cool box uses two thick copper plates to create a quasi-vertical TG, whose values vary linearly in the horizontal direction. A fluid circulation maintains the copper plates at the desired temperature.

Temperature probes were used in order to monitor the temperature at different points of the snow layer. The snow, with density $\sim 280 \mathrm{~kg} \mathrm{~m}^{-3}$, was submitted to a permanent temperature gradient ranging from $3 \mathrm{~K} \mathrm{~m}^{-1}$ at one side of the device to $16 \mathrm{~K} \mathrm{~m}^{-1}$ at the other side. After 3 weeks of experiment at an average temperature of $-3^{\circ} \mathrm{C}$, samples $4 \mathrm{~cm}$ in diameter were cored and impregnated at $-8^{\circ} \mathrm{C}$ with 1 -chloronaphthalene. The cold room was then set to $-25^{\circ} \mathrm{C}$ in order to completely freeze the samples and allow further machining. Smaller cores $9 \mathrm{~mm}$ in diameter were then extracted with a precision hole-saw, sealed inside thin PMMA boxes and kept ready for tomography acquisition at $-50^{\circ} \mathrm{C}$.

\subsection{Image obtention}

Three-dimensional images of snow samples were obtained at the ID19 beamline of the European Synchrotron Radiation Facility (ESRF), Grenoble, France, by X-ray absorption microtomography using a specially designed refrigerated cell (Brzoska and others, 1999; Coléou and others, 2001). All the images were obtained at $18 \mathrm{keV}$, with a voxel (volume element) size of $4.91 \mu \mathrm{m}$. The grey-level images obtained 

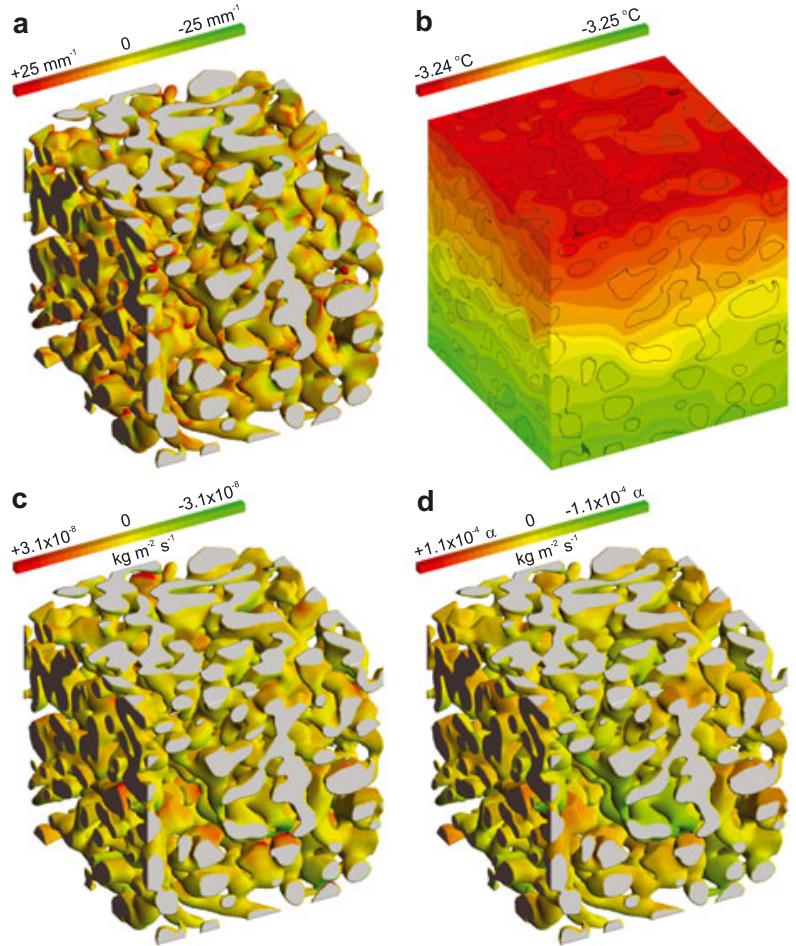

Fig. 2. Three-dimensional representations of a slightly faceted snow sample imaged after 3 weeks of TG metamorphism $\left(\mathrm{TG}=3 \mathrm{~K} \mathrm{~m}^{-1}\right)$. (a) Curvature map; (b) temperature field; and (c,d) computed incoming matter fluxes for the diffusive (c) and reactive (d) models. Edge size of the volume: 300 voxels $\sim 3 \mathrm{~mm}$.

were reconstructed at the ESRF and contoured using a semiautomatic procedure.

To allow fast processing times for our image analysis algorithms, the resolution of the 3-D images was reduced by a factor of two in the three axes. In all the 3-D snow images presented in this paper, one voxel therefore corresponds to $9.82 \mu \mathrm{m}$. More information about core preparation and image processing can be found in Flin and others (2003).

\section{MODEL APPLICATION TO 3-D IMAGES}

As shown in section 2, the sign of $j$ implies the faceting or the rounding of the shapes. We can therefore check the validity of our faceting model using 3-D images.

We tested the model on two samples of metamorphosed snow: a sample submitted to a TG of $3 \mathrm{Km}^{-1}$ (Fig. 2) and another submitted to a TG of $16 \mathrm{~K} \mathrm{~m}^{-1}$ (Fig. 3). To compute $j$, we need to estimate both the pressure and the temperature close to the ice-pore interface (Equation (2)).

\subsection{Temperature field}

Temperature maps (Figs $2 \mathrm{~b}$ and $3 \mathrm{~b}$ ) can be obtained by modelling the heat transfer into the 3-D snow structure. As mentioned in section 2.1, convection and latent-heat effects in snow are negligible for the considered TGs. Consequently, the temperature field was computed by considering only conduction effects in both the ice and the pores of the snow structure. This was accomplished using a finite volume scheme (Patankar, 1980). Because of the large meshes used, an iterative approach was employed.

The initial boundary conditions were fixed according to the experimental measurements. The temperatures at the top
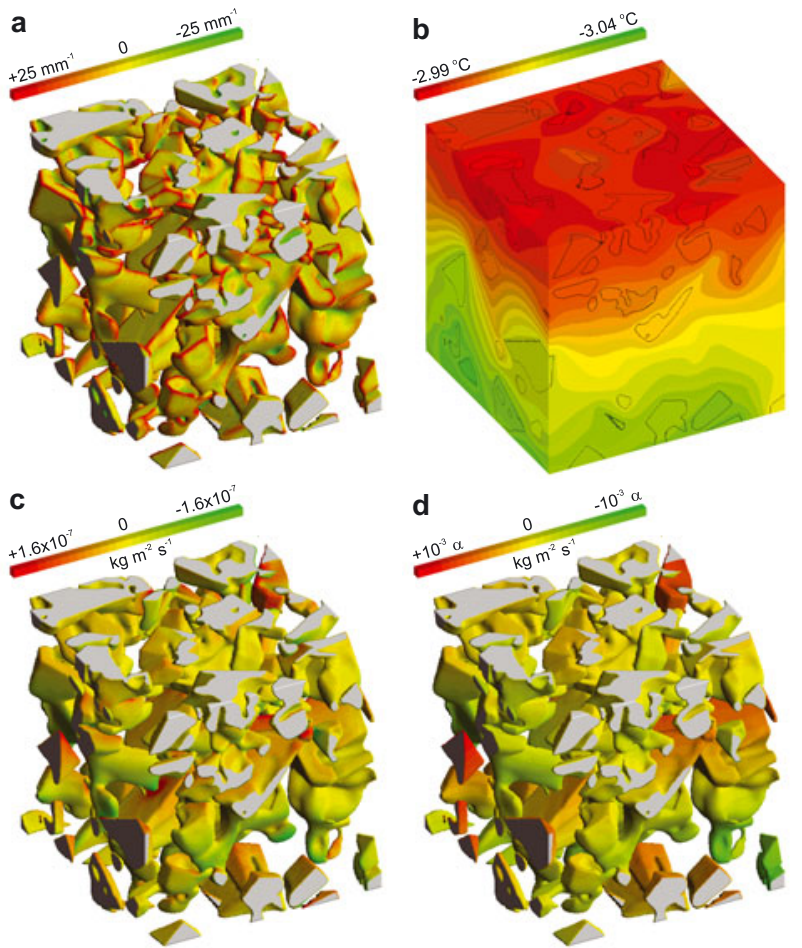

Fig. 3. Same as Figure 2, but for a faceted snow sample imaged after 3 weeks of TG metamorphism $\left(\mathrm{TG}=16 \mathrm{~K} \mathrm{~m}^{-1}\right)$.

and bottom of the 3-D images were estimated from the experimental temperature data by linear interpolation. For the model validation, a cube of $3 \times 3 \times 3 \mathrm{~mm}^{3}$ was extracted from the centre of the wider $\left(6 \times 6 \times 6 \mathrm{~mm}^{3}\right) 3$-D field initially obtained, in order to remove possible side effects.

\subsection{Vapour-pressure field}

Vapour-pressure maps can be obtained using an algorithm recently developed by Brzoska and others (2008) for isothermal metamorphism. On the grain surface $S$ the ice is locally considered to be in equilibrium with the vapour, providing a Dirichlet's boundary condition to the vapour field:

$$
\forall \vec{r} \in S, P(\vec{r})=P_{\text {sat }}(C, T),
$$

where $\vec{r}$ is the position vector. $P_{\text {sat }}(C, T)$ is the local saturation vapour pressure at temperature $T$ for a surface of curvature $C\left(\mathrm{~m}^{-1}\right)$. This quantity can be obtained by combining the Kelvin and Clausius-Clapeyron laws to obtain

$$
P_{\text {sat }}(C, T)=P_{0} \exp \left[\frac{1}{R T}\left(\Delta h_{\text {sub }} \frac{T-T_{0}}{T_{0}}+2 \gamma \Omega C\right)\right],
$$

where $P_{0}$ is the saturation vapour pressure for an infinite plan at some temperature $T_{0}, \Delta h_{\text {sub }}$ is the molar enthalpy of sublimation $\left(\mathrm{J} \mathrm{mol}^{-1}\right), \gamma$ is the surface tension of the interface $\left(\mathrm{J} \mathrm{m}^{-2}\right)$ and $\Omega$ is the molar volume of ice $\left(\mathrm{J} \mathrm{m}^{-2}\right)$.

Elsewhere, $P$ should obey the stationary equation of diffusion:

$$
\Delta P(\vec{r})=0 .
$$

If the temperature (see section 4.1) and curvature (Flin and others, 2004) fields in the snow microstructure (Figs 2a and $\mathrm{b}$ and $3 \mathrm{a}$ and $\mathrm{b}$ ) are known and Equation (5) is solved, one can obtain the vapour pressure map in the pore space of a snow image. 


\subsection{Results}

Once both the temperature and vapour pressure fields are computed, one can estimate the local matter fluxes at the interface by digitizing Equation (2). The flux maps obtained for the snow samples submitted to $\mathrm{TG}=3 \mathrm{Km}^{-1}$ and $\mathrm{TG}=16 \mathrm{~K} \mathrm{~m}^{-1}$ are presented in Figures $2 \mathrm{c}$ and $3 \mathrm{c}$, respectively. For each snow sample, the flux map obtained with the present model (Figs 2c and 3c) is compared to the flux map computed for a reaction-limited mechanism of effective sticking coefficient $\alpha$ as modelled by Flin and others (2007) (Figs 2d and 3d).

For a better visualization of the faceted shapes, all the images in Figures 2 and 3 are presented upside down. The top (bottom) of the images corresponds to the lowest (highest) and warmest (coolest) side of the physical sample. From both of the diffusive and reactive flux maps, it is clear that, for convex shapes, predicted condensation sites $(j>0$, orange colour) correspond to faceted zones while rounded forms are defined by sites where $j<0$ (sublimation, green colour).

\section{CONCLUSION}

A simple model describing the TG metamorphism of snow has been presented. This model, similar to a previously developed model (Flin and others, 2007), takes into account the local variation of the saturating vapour pressure with temperature to explain the matter exchanges observed during the TG metamorphism. In the present model, however, vapour diffusion in the pore space is considered as the limiting mechanism of the metamorphism.

The two models can determine locally whether the ice is condensing or subliming, depending on both the pressure and temperature fields in the snow volume. As in the previously proposed model, the diffusive model is consistent with several observations (Yosida and others, 1955; Colbeck, 1983) suggesting that during the TG metamorphism grains sublime at their top parts by generating rounded shapes while their bottom parts grow into faceted shapes. More recent time-lapse observations also support this interpretation (Sato and Kamata, 2000; Adams and others, 2008).

By comparing the result of the vapour diffusion model with those of the evaporation-condensation model, one can observe the following.

1. As expected, the main difference between the two models is that the diffusive model is locally sensitive to the distance to vapour sources and sinks situated on the icepore interface, whereas the evaporation-condensation model does not take such distances into account.

2. The flux maps of both models are not significantly different. This probably means that the choice of the matter transfer mechanism does not play a fundamental role in the formation of the typical snow morphology obtained under temperature gradients. The local temperature gradients appearing in the snow microstructure, due to strong differences in conductivities between the ice and the pore space, seem to be the driving force of the TG metamorphism.

3. Quantitative results obtained for the two models are close for a value of $\alpha$ ranging from $10^{-3}$ to $10^{-4}$. This value is of the same order as other $\alpha$ values obtained by other means (Libbrecht, 2003; Flin and others, 2007; Brzoska and others, 2008). Is this estimated coefficient really a sticking coefficient, or is it in fact accounting for averaged diffusive effects in the pore space? This can possibly be answered by simulating the morphological evolution of the snow structure with time. By providing a method of computing the vapour fluxes incoming to the ice surface, the present model offers interesting outcomes in this direction.

\section{ACKNOWLEDGEMENTS}

We thank the staff of the ESRF ID19 beamline and especially J. Baruchel and X. Thibault for their help in the tomographic acquisition process. R.A. Pieritz is thanked for his contribution in obtaining the temperature fields. We are also grateful to C. Coléou and B. Lesaffre who assisted with the sample preparation and image preprocessing. Special thanks are due to B. Fyffe for proofreading the manuscript.

\section{REFERENCES}

Adams, E.E., S.M. Jepsen and B. Close. 2008. A bonding process between grains in mechanically disaggregated snow. Ann. Glaciol., 48, 6-12.

Brun, E. and F. Touvier. 1987. Etude expérimentale de la convection thermique dans la neige. J. Phys. I [Paris], 48(C1), 257-262.

Brzoska, J.-B. and 7 others. 1999. 3D visualization of snow samples by microtomography at low temperature. ESRF Newsl. 32, 22-23.

Brzoska, J.-B., F. Flin and J. Barckicke. 2008. Explicit iterative computation of diffusive vapour field in the 3-D snow matrix: preliminary results for low flux metamorphism. Ann. Glaciol., 48, 13-18.

Colbeck, S.C. 1983. Theory of metamorphism of dry snow. J. Geophys. Res., 88(C9), 5475-5482.

Colbeck, S.C. 1997. A review of sintering in seasonal snow. CRREL Rep. 97-10.

Coléou, C., B. Lesaffre, J.-B. Brzoska, W. Ludwig and E. Boller. 2001. Three-dimensional snow images by X-ray microtomography. Ann. Glaciol., 32, 75-81.

de Quervain, M. 1963. On the metamorphism of snow. In Kingery, W.D., ed. Ice and snow: properties, processes, and applications. Cambridge, MA, MIT Press.

de Quervain, M.R. 1973. Snow structure, heat, and mass flux through snow. IAHS Publ. 107 (Symposium at Banff 1972 - The Role of Snow and Ice in Hydrology), 203-226.

Flin, F., J.-B. Brzoska, B. Lesaffre, C. Coléou and R.A. Pieritz. 2003. Full three-dimensional modelling of curvature-dependent snow metamorphism: first results and comparison with experimental tomographic data. J. Phys. D, 36(10A), A49-A54.

Flin, F., J.-B. Brzoska, B. Lesaffre, C. Coléou and R.A. Pieritz. 2004. Three-dimensional geometric measurements of snow microstructural evolution under isothermal conditions. Ann. Glaciol., 38, 39-44.

Flin, F., J.-B. Brzoska, R.A. Pieritz, B. Lesaffre, C. Coléou and Y. Furukawa. 2007. The temperature gradient metamorphism of snow: model and first validations using x-ray microtomographic images. In Kuhs, W.F., ed. Physics and chemistry of ice. Cambridge, Royal Society of Chemistry, 181-189.

Furukawa, Y. and S. Kohata. 1993. Temperature dependence of the growth form of negative crystal in an ice single crystal and evaporation kinetics for its surfaces. J. Cryst. Growth, 129(3-4), 571-581.

Kaempfer, T.U., M. Schneebeli and S.A. Sokratov. 2005. A microstructural approach to model heat transfer in snow. Geophys. Res. Lett., 32(21), L21503. (10.1029/2005GL023873.)

Knight, C.A. 1966. Formation of crystallographic etch pits on ice, and its application to the study of hailstones. J. Appl. Meteorol., 5(5), 710-714. 
Knight, C.A. and N.C. Knight. 1965. Negative crystals in ice: a method for growth. Science, 150(3705), 1819-1821.

Legagneux, L. and F. Dominé. 2005. A mean field model of the decrease of the specific surface area of dry snow during isothermal metamorphism. J. Geophys. Res., 110(F4), F04011. (10.1029/2004JF000181.)

Libbrecht, K.G. 2003. Growth rates of the principal facets of ice between $-10^{\circ} \mathrm{C}$ and $-40^{\circ} \mathrm{C}$. J. Cryst. Growth, 247(3-4), 530-540.

Markov, I.V., ed. 1995. Crystal growth for beginners: fundamentals of nucleation, crystal growth, and epitaxy. Second edition. Singapore, World Scientific Publishing.

Mutaftschiev, B. 2001. The atomistic nature of crystal growth. Berlin, etc., Springer-Verlag. (Springer Series in Materials Science 43.)
Patankar, S.V. 1980. Numerical heat transfer and fluid flow. New York, Hemisphere Publishing.

Sato, A. and Y. Kamata. 2000. Observations of depth hoar growth by time-lapse motion pictures. In Hartman, P., ed. Proceedings of the 2000 Cold Region Technology Conference. Vol. 16. Sapporo, Hokkaido Development Engineering Center, 143-147.

Sommerfeld, R.A. 1983. A branch grain theory of temperature gradient metamorphism in snow. J. Geophys. Res., 88(C2), 1484-1494.

Yosida, Z. and 6 others. 1955. Physical studies on deposited snow. I. Thermal properties. Contrib. Inst. Low Temp. Sci., Ser. A, 7, $19-74$. 